\title{
An Experimental Study on Seismic Performance of Steel Truss Coupling Beams with Buckling-restrained Brace
}

\author{
Weidong Sun, Kang Li* and Xinyu Niu
}

Jilin Key Laboratory of Disaster Prevention and Reduction, Faculty of Civil Engineering, Changchun Institute of Technology, Changchun, 130012, P.R.China

\begin{abstract}
Through the pseudo-static test on the steel truss coupling beams with buckling-restrained brace, the bearing capacity, deformation capacity, hysteresis curve, skeleton curve, ductility, Energy Dissipation and stiffness degradation of such coupling beam are understood. The test results show that the steel truss coupling beams with buckling-restrained brace is characterized by bigger bearing capacity, higher ductility and good plastic energy dissipation capacity.
\end{abstract}

Keywords: Buckling-restrained brace, ductility, energy dissipation, steel truss coupling beams.

\section{PREFACE}

Characterized by high stiffness and strong lateral resistant ability, the concrete shear wall is widely used in the high-rise building construction system, among which, the hybrid coupled wall is the most typical and widely used shear wall. In the concrete coupled shear wall, the coupling beam is the key component that affects the seismic performance of shear wall structure. Under the action of small seisms, the coupling beam should provide the coupling wall column with the stronger binding effect, strengthen the lateral stiffness, reduce the lateral deformation and increase the bearing capacity of the structure; when the rare earthquake occurs, the coupling beam should yield before the coupling wall column so as to consume the earthquake energy and weaken the seismic response through the plastic deformation of the coupling beam [1]. The concrete coupling beam has some common shortcomings, including heavy selfweight, low bearing capacity, insufficient ductility, limited energy dissipation capacity and difficult post-earthquake reconstruction [1]. In recent years, some foreign scholars propose to use the solid-web steel coupling beam to replace the concrete coupling beam; the test and theoretical research results show that the steel coupling beam designed rationally is equipped with sufficient strength, stiffness and toughness and the hybrid coupled wall construction system composed by steel coupling beam and concrete coupling wall column has good seismic performance. Through applying the steel coupling beam, the complex reinforcement and structural measures of concrete coupling beam can be avoided, the construction difficulty and cost can be reduced and the structure can be repaired and changed after disaster [2]. Some developed countries, including America and Canada, have launched the corresponding design codes and suggestions [3].

\footnotetext{
*Address correspondence to this author at the School Faculty of Civil Engineering, Changchun Institute of Technology, Changchun, 130012, P.R.China; Tel: 18687083206; E-mail: 565611332@qq.com
}

In 2003, professor DENG Zhiheng in Guangxi University put forward the construction system of steel truss coupling beam [4], designed the coupling beam into the truss composed by hot-rolled section steel or welding type steel and set the friction energy dissipation damping control device on the intermediate support of truss. The self-weight of steel truss coupling beam is lighter than that of solid-web steel coupling beam and the additional damping device can realize the energy dissipation and seismic reduction more efficiently. However, the friction damper has certain disadvantages, for example, it does not have self-resetting ability and the friction surface may produce cold sticking or cold set during the long-term static contact process and the frictional force of sliding surface may degenerate [5].

Based on the foreign and domestic researches on the coupling beam, the author puts forward the configuration form of the steel coupling beam with buckling-restrained brace and such steel coupling beam still uses truss configuration form, however, part or all of the bars of the truss apply the buckling-restrained brace which can act as the stressed bar of the coupling beam during the normal use phase and give full play to ductility and energy dissipation capacity during the severe earthquakes [6]. The bucklingrestrained brace is characterized by low cost, good Energy Dissipation, stable hysteresis behavior, low-cycle fatigue behavior, good adaptability to environment and temperature and long-term stable performance [7]. At present, the research on the buckling-restrained brace is relatively mature and it is successfully used in the frame structures, such as stadium and gymnasium and office building.

In order to study the seismic performance of the steel coupling beam with buckling-restrained brace, the research group has completed the quasi-static tests on the coupling beam components of two kinds of buckling-restrained braces, mainly studying the deformation capacity, failure feature, hysteresis curve, skeleton curve, ductility, Energy Dissipation and stiffness degradation of the steel coupling beam with buckling-restrained brace. 


\section{OVERVIEW OF THE TEST}

\subsection{Test Design}

On the basis of the requirements of the two frameworks the actual coupling beam size of the coupled shear wall and the limiting value of the story displacement of the reference structure, two coupling beam component models, GLL-1 and GLL-2, are designed according to the contraction scales of 1/2, as shown in Fig. (1) and Fig. (2). In order to simulate the force state of coupling beam in the coupling wall column, the loading scheme in Fig. (3) is applied. The top and lower chords and buckling-restrained brace are designed by using the finite element analysis software Midas Building and the yield point of the buckling-restrained brace should be controlled after the angle limit of small seism and before that of severe earthquake. The chord member is embedded in the shear wall and the anchorage length of the chord member is designed after referring to the research results of the connecting structures between the steel beams and coupling wall columns. The concrete design grade of the top and lower concrete end pieces is $\mathrm{C} 30$, the height is shown in Fig. (1) and Fig. (2) and the thickness is $300 \mathrm{~mm}$, and the longitudinal Fig. (4) and Fig. (5) is GLL-1 and GLL-2 failure graph steel and stirrup are deployed according to the calculation.

\subsection{Member Bar Parameter and its Performance Index of Material Mechanics}

The parameter of coupling beam bar is in Table $\mathbf{1}$ and its performance index of material mechanics is in Table 2.

According to the field test, the average value of the compression strength of the concrete cube is $31.5 \mathrm{MPa}$ for GLL-1 and it is $39.5 \mathrm{MPa}$ for GLL-2.

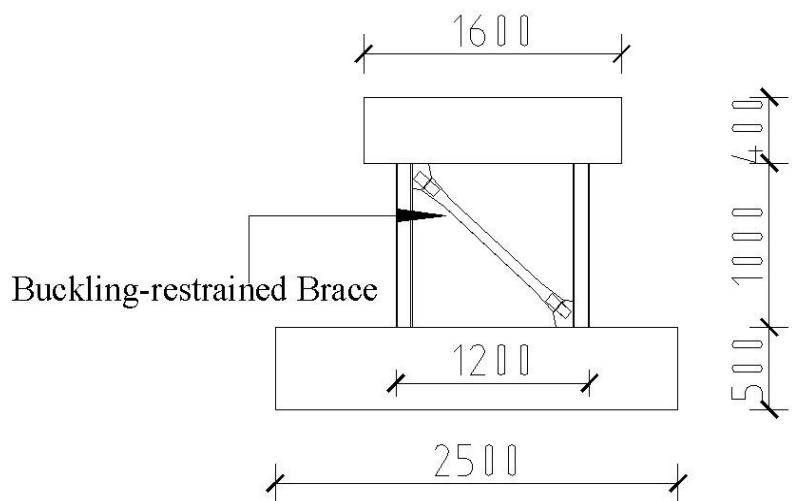

Fig. (1). GLL-1 Size (Unit:mm).

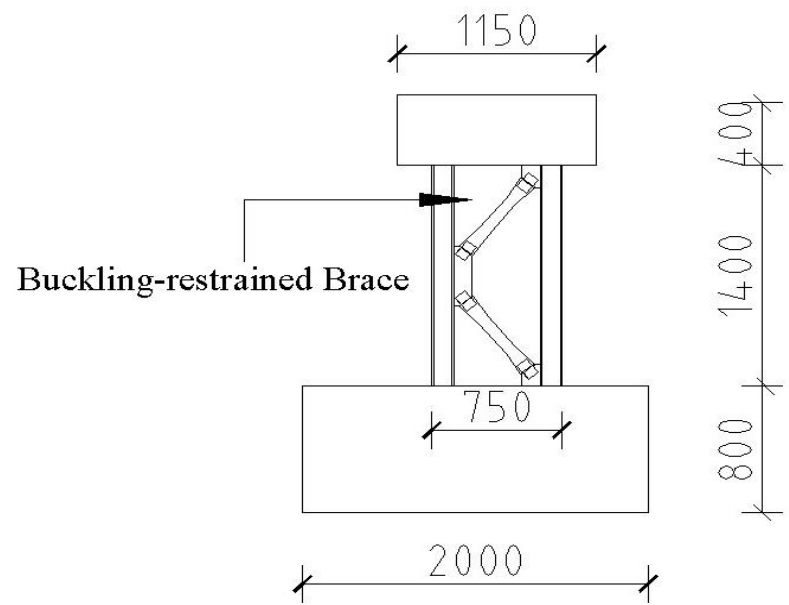

Fig. (2). GLL-2 Size (Unit:mm).

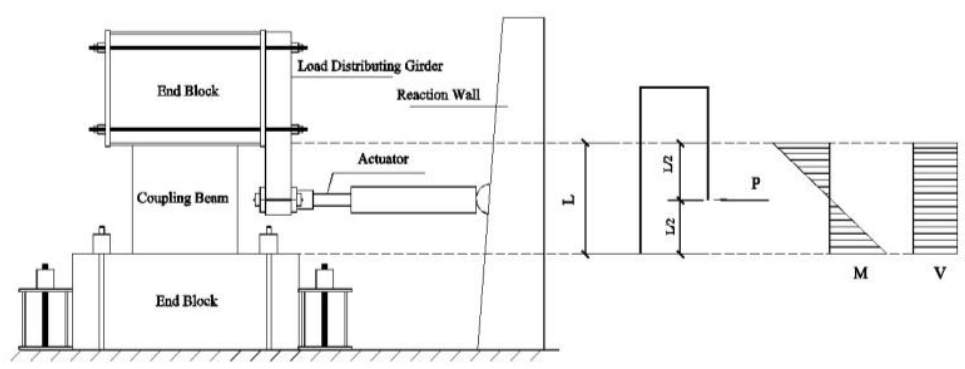

Fig. (3). Component loading scheme.

Table 1. Parameter list of coupling beam bar.

\begin{tabular}{|c|c|c|c|c|}
\hline $\begin{array}{c}\text { Component } \\
\text { Number }\end{array}$ & $\begin{array}{c}\text { Steel Type of Chord } \\
\text { Member }\end{array}$ & $\begin{array}{c}\text { Steel Grade of Chord } \\
\text { Member }\end{array}$ & $\begin{array}{c}\text { Core Section of Buckling } \\
\text { Restrained Brace }\end{array}$ & $\begin{array}{c}\text { Core Grade of Buckling } \\
\text { Restrained Brace }\end{array}$ \\
\hline \hline GLL-1 & $\mathrm{H} 100 \times 100 \times 6 \times 8$ & $\mathrm{Q} 345$ & $60 \times 8$ & $\mathrm{Q} 235$ \\
\hline GLL-2 & $\mathrm{H} 125 \times 125 \times 6.5 \times 9$ & $\mathrm{Q} 345$ & $70 \times 8$ & $\mathrm{Q} 235$ \\
\hline
\end{tabular}

Table 2. Mechanical performance index of coupling beam steel.

\begin{tabular}{|c|c|c|c|c|}
\hline Steel Type & Yield Strength & Ultimate Strength & Elasticity Modulus & Steel Yield Strain \\
\hline \hline Core of Buckling Restrained Brace & 270 & 425 & $2.01 \times 10^{5}$ & 1238 \\
\hline H Type Steel & 330 & 508.3 & $2.05 \times 10^{5}$ & 1609 \\
\hline
\end{tabular}




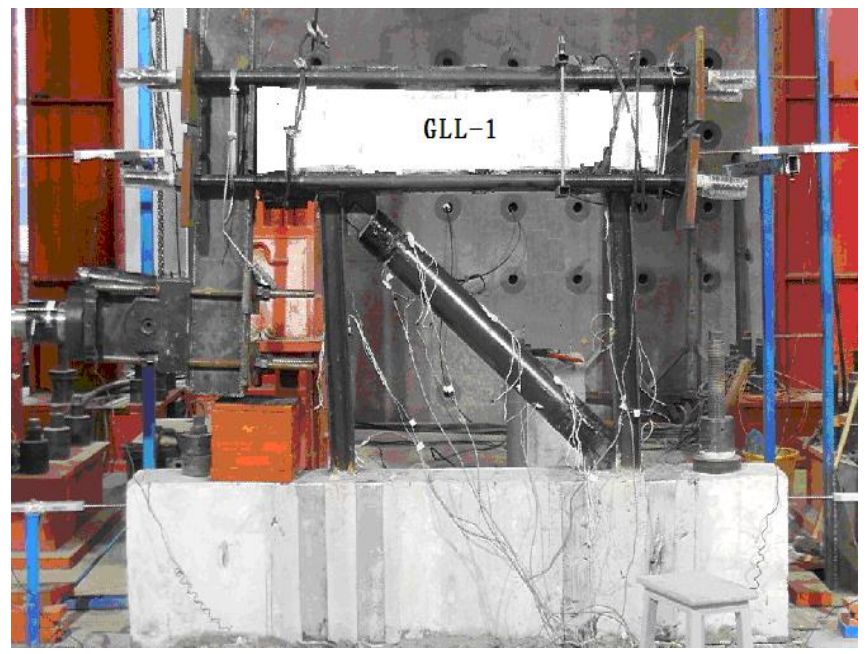

Fig. (4). GLL-1 failure graph.

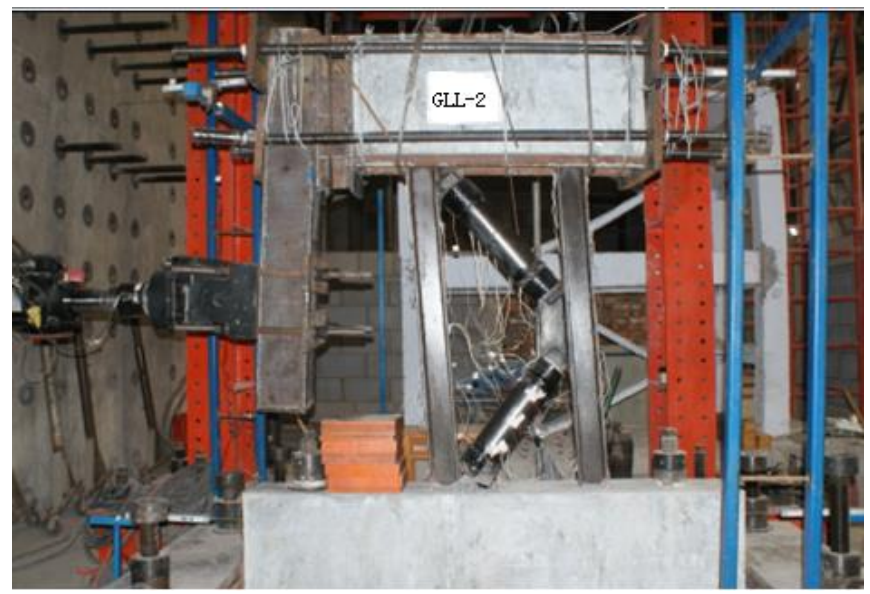

Fig. (5). GLL-2 failure graph.

According to the field test, the average value of the compression strength of the concrete cube is $31.5 \mathrm{MPa}$ for GLL-1 and it is $39.5 \mathrm{MPa}$ for GLL-2.

\subsection{Test Devices}

In the test, the 45 ton electro-hydraulic servo loading device manufactured by America MTS is used and the DH3816 static contingency test system is applied to record the steel strain.

\subsection{Loading System}

The dual control of load and displacement is used to apply the horizontal load: before the yield of the component, apply the load to control the stepping loading and circulate once on each corresponding load step; after the yield of the component, apply the displacement control, take the multiple of the yield displacement as the graduation to control load and circulate twice on each corresponding load step.

\section{TEST PROCESS}

\subsection{Test Phenomena}

During the preliminary stage of the load, the P- $\Delta$ curve of the entire component is in the linear elasticity stage, the strain of the chord member is small and has no obvious deformation and the coupling beam shows higher stiffness. After the strain of the buckling-restrained brace increases sharply, the P- $\Delta$ curve enters into elastic-plastic stage, the amplification of the horizontal displacement of the component increases and the readings of the strain gauges of the top and lower chords are still in elastic stage. If the component displacement increases obviously, it means that the component has entered into the yield stage and then it should be controlled by displacement. When the displacement is $\Delta y$ or $2 \Delta y$, the chord member has no obvious deformation and the deformation of bucklingrestrained brace increases; when the displacement is $3 \Delta \mathrm{y}$, the distortion flexion appears on the joint between the chord member end and buckling-restrained brace and the microcrack appears on the anchor positions of the supports on both ends of the chord member; when the displacement is $4 \Delta y$, the distortion flexion of the structural steel on the node increases obviously, some strain gauges fall off and the bearing capacity falls badly. Henceforth, the entire coupling beam is destroyed; due to the good ductility of the steel structure, the whole failure process is relatively slow. The anchorage length of the chord member on the support is rational and thus the concrete on the foundation only has microcrack.

\section{TEST RESULT AND ANALYSIS}

\subsection{Bearing Capacity and Displacement Value of Component}

The experimental values of yield loads, ultimate loads, failure loads of Component GLL-1 and GLL-2 and the corresponding displacement values are shown in Table $\mathbf{3}$. From the table, it can be seen that the yield loads, ultimate loads, failure loads of Component GLL-1 and GLL-2 are relatively big, declaring that the bearing capacity of such type of coupling beam is large.

\subsection{Energy Dissipation Capacity of Component}

\subsubsection{Load-Displacement Hysteresis Curve}

According to the test results, the hysteresis curves of GLL-1 and GLL-2 are obtained, as shown in Fig. (6) and Fig. (7).

Table 3. Test data table.

\begin{tabular}{|c|c|c|c|c|c|}
\hline Component Number & Yield Load(kN) & Ultimate Load (kN) & Failure Load(kN) & $\begin{array}{c}\text { Yield Displacement } \\
(\mathbf{m m})\end{array}$ & $\begin{array}{c}\text { Failure Displacement } \\
(\mathbf{m m})\end{array}$ \\
\hline \hline GLL-1 & 260 & 290 & 247 & 24.4 & 120.23 \\
\hline GLL-2 & 280 & 315 & 265 & 30.9 & 138.76 \\
\hline
\end{tabular}




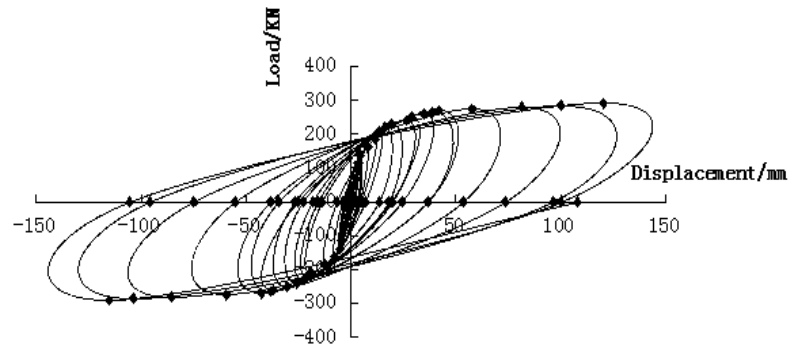

Fig. (6). Hysteresis curve of GLL-1 test.

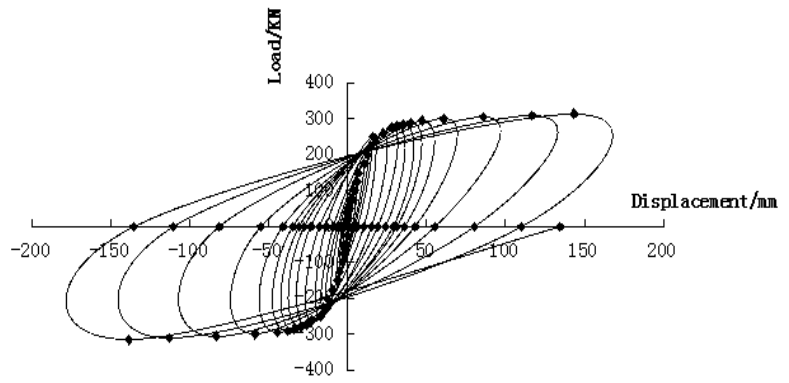

Fig. (7). Hysteresis curve of GLL-2 test.

It can be seen from the hysteresis curves of component GLL-1 and GLL-2 that during the initial stage of the load, the load-displacement hysteresis curve is basically linear, the component is in elastic stage and the residual deformation and the energy dissipation capacity are small when unloading; after the buckling-restrained brace enters into the plastic stage, the stiffness of the component stiffness reduces and the deformation increases; during the final circulations, the hysteresis curve pinches in a small way and intersects with the previous hysteresis curve in some parts because the residual strain increases during the unloading process after the buckling-restrained brace reaches ultimate strength. Seen from the failure process, the hysteresis curve is in clostridial form and is plump, its area is large and it has no obvious pinching and slip phenomena, showing that the plastic deformation capacity of the whole component is strong and has good seismic performance and energy dissipation capacity and the stiffness reduces slowly.

\subsubsection{Equivalent Viscous Damping Ratio}

The equivalent viscous damping ratio $h_{e}$ can be measured through the area surrounded by the hysteresis curve and the form (as shown in Fig. (8)) and it can be calculated through the following formula:

$$
h_{e}=\frac{1}{2 \pi} \times \frac{\text { Hysteresis Curve Area }}{\text { Triangle Area }}=\frac{S_{A B C D}}{2 \pi\left(S_{\triangle O B E}+S_{\triangle O D F}\right)}
$$

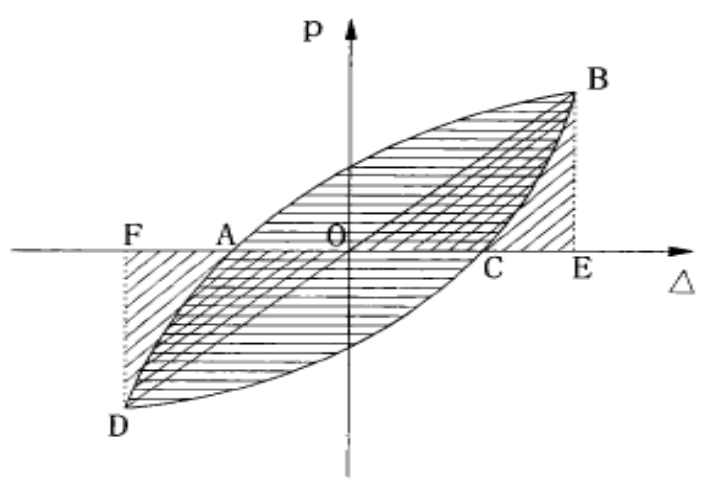

Fig. (8). Schematic system of calculation of equivalent viscous damping ratio.

If the value of $h_{e}$ is bigger, the energy dissipation capacity is better. The equivalent viscous damping ratio $h_{e}$ of GLL-1 and that of GLL-2 are shown in Table $\mathbf{4}$ and $\mathbf{5}$.

According to the above data, the equivalent viscous damping ratio he of the component increases along with the increment of displacement, the equivalent viscous damping ratio of reinforced concrete structure is around 0.1 [8] and the viscosity ratio of the new steel truss coupling beam is around

Table 4. Equivalent viscous damping ratio $h_{\mathrm{e}}$ of GLL-1.

\begin{tabular}{|c|c|c|c|}
\hline Displacement $(\mathbf{m m})$ & Hysteresis Curve Area & Triangle Area & $\boldsymbol{h}_{\mathbf{e}}$ \\
\hline \hline 24.4 & 12187.35 & 6280.25 & 0.309 \\
\hline 48.8 & 22279.83 & 11390.49 & 0.311 \\
\hline 73.2 & 44531.72 & 23398.93 & 0.303 \\
\hline 97.6 & 58795.29 & 29019.31 & 0.323 \\
\hline
\end{tabular}

Table 5. Equivalent viscous damping ratio $h_{\mathrm{e}}$ of GLL-2.

\begin{tabular}{|c|c|c|c|}
\hline Displacement (mm) & Hysteresis Curve Area & Triangle Area & $\boldsymbol{h}_{\boldsymbol{e}}$ \\
\hline \hline 30.9 & 17358.08 & 8507.66 & 0.324 \\
\hline 61.8 & 35786.50 & 17944.50 & 0.317 \\
\hline 92.7 & 72677.54 & 36175.63 & 0.320 \\
\hline 123.6 & 86746.56 & 43725.05 & 0.316 \\
\hline
\end{tabular}


0.2 [4]; it can be seen from Tables $\mathbf{2 - 4}$ and Tables $\mathbf{2 - 5}$ that the equivalent viscosity ratios of component GLL-1 and component GLL-2 are all larger than 0.3, showing that the component has good energy dissipation capacity.

\subsubsection{Skeleton Curve}

It can be seen from the skeleton curves of component GLL-1 and component GLL-2, (as shown in Fig. (9 and 10) that the skeleton curve of the coupling beam of such truss has obvious inflection point and the descent stage of the bearing capacity during the later period is long and gradual after the load reaches the ultimate bearing capacity, showing that its stiffness reduces slowly, its deformation capacity is strong and it has good ductility, seismic capacity and energy dissipation capacity.

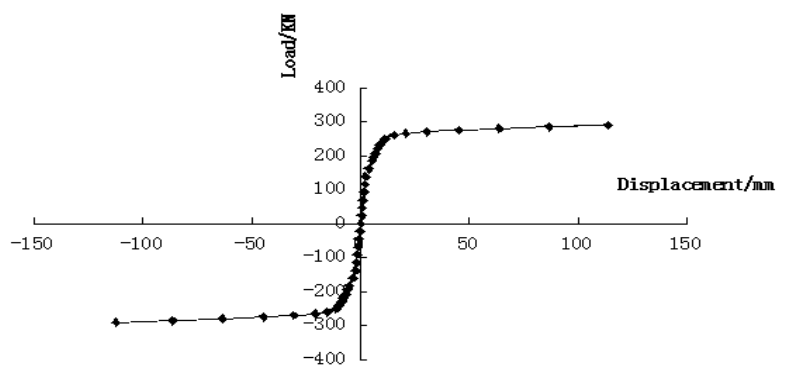

Fig. (9) Skeleton curve of GLL-1.

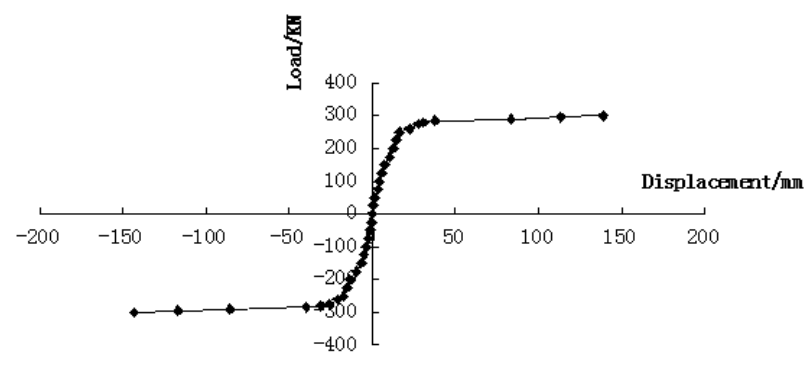

Fig. (10). Skeleton curve of GLL-2.

\subsubsection{Component Ductility}

The deformation capacities of the structure, the component or the section of the component with good ductility during the later period are large and can absorb a certain amount of energy after yielding or reaching the maximum bearing capacity so as to avoid fracture. The displacement ductility coefficient can reflect the component ductility macroscopically; therefore, in this thesis, the linear displacement ductility coefficient is used to get the deformation (displacement) during component failure and the deformation (displacement) ratio when yielding. It is generally shown by $\mu$ :
$\mu=\Delta_{\mathrm{u}} / \Delta_{\mathrm{y}}$

In the formula: $\Delta_{\mathrm{u}} \longrightarrow$ the deformation when the bearing capacity of the component drops to $85 \%$ of the ultimate bearing capacity.

$\Delta y \_$the corresponding deformation during the yield load of the component.

Table $\mathbf{6}$ is the data table of the displacement ductility of GLL-1 and GLL-2 .

The displacement ductility coefficient of the reinforced concrete coupling beam of the common reinforcement is between 2.0 and 3.0[8], however, the coefficients of GLL-1 and GLL-2 are all above 4.0, showing that such steel truss coupling beam has good ductility and seismic performance.

\subsubsection{Stiffness Degradation}

In order to reflect the stiffness degradation of the structural component under the action of low cyclic loading, the average stiffness $K_{i}$ loaded during each circulation under the action of repeated loading is gotten to analyze, expressed as below:

$K_{i}=\frac{\left|+P_{i}\right|+\left|-P_{i}\right|}{\left|+\Delta_{i}\right|+\left|-\Delta_{i}\right|}$

In the formula: $P_{i}$ is the corresponding peak load when the displacement ductility coefficient is $i$;

$\Delta_{i} \longrightarrow$ is the corresponding peak displacement when the displacement ductility coefficient is $i$.

The stiffness degradation curves of GLL-1 and GLL-2 are shown in Fig. (11) and Fig. (12).

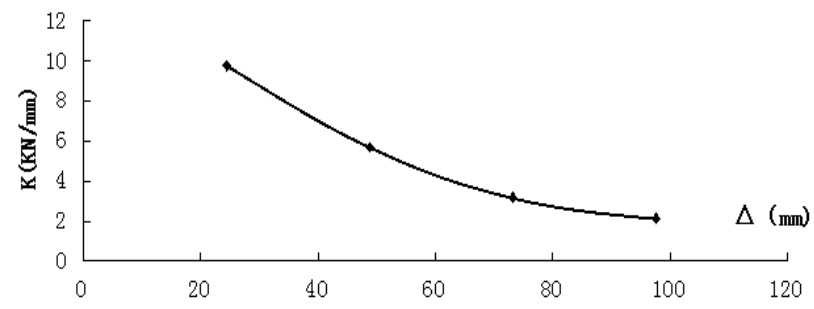

Fig. (11). Stiffness degradation curve of GLL-1.

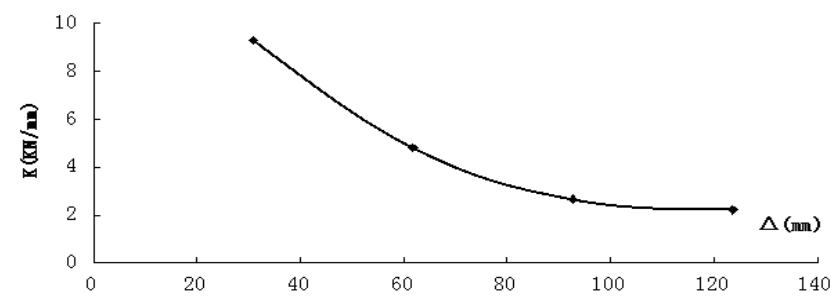

Fig. (12). Stiffness degradation curve of GLL-2.

Table 6. Displacement Ductility Coefficients of GLL-1 and GLL-2

\begin{tabular}{|c|c|c|c|}
\hline Component Number & Yield Displacement(mm) & Ultimate Displacement(mm) & Ductility Coefficient \\
\hline \hline GLL-1 & 24.4 & 120.23 & 4.93 \\
\hline GLL-2 & 30.9 & 138.76 & 4.49 \\
\hline
\end{tabular}


It can be seen from the two stiffness degradation curves that the stiffness degradation curve is gradual, showing that the stiffness degradation is slow, which reflects the good ductility of the steel coupling beam with buckling-restrained brace. The stiffness of monoclinic layout decreases more quickly than that of the splayed layout, showing that the inverted "V" layout plays a more important role in the stiffness of coupling beam.

\section{CONCLUSIONS}

(1) Under the action of low cyclic loading, the steel truss coupling beams with buckling-restrained brace has higher bearing capacity.

(2) The hysteresis curves of the monoclinic and splayed layouts of the buckling-restrained brace are all plump; the equivalent viscosity ratios of the two coupling beams are more than 0.3 , showing that the component has good energy dissipation capacity.

(3) The descent stage of the bearing capacity of the steel truss coupling beams with buckling-restrained brace during the later period is long and gradual and the stiffness degradation is slow after the load reaches the ultimate bearing capacity, showing the good ductility of the steel coupling beam with the buckling-restrained brace. The inverted "V" layout plays a more important role in the stiffness of coupling beam than the monoclinic layout.

(4) The length of the chord member applied in the test and its connection mode that embeds it in the concrete coupling wall column are feasible.

\section{CONFLICT OF INTEREST}

The author confirms that this article content has no conflict of interest.

\section{ACKNOWLEDGEMENTS}

This project was financially supported by the Education Department of Jilin Province, WANG Yu from Midas company and professor WANG Baoyuan、ZOU Xiangyang from Changchun Institute of Technology. For that I am very greatful.

\section{REFERENCES}

[1] Y. Wu, Y. Li, Q. Zhang, and J. Fan, "Seismic design of hybrid coupled walls in United States," Journal of Building Structures, vol. 12, pp. 137-143, 2011.

[2] S. EI-Tawil, K.A. Harries, P.J. Fortmey, B. Shahrooz, and Y. Kurama, "Seismic design of hybrid coupled wall systems: state of the art," Journal of Structural Engineering, ASCE, vol. 136, no. 7, pp. 755-769, 2010.

[3] ACI318-08 Building code requirements for reinforced concrete and commentary, Farmington Hills Michigan, USA: American Concrete Institute, 2008.

[4] Z. Deng, Q. Lin, Q. Hu, Z. Pan, and D. Xu, "Test for a seismic behavior of new steel truss coupling beams," Journal of Vibration and Shock, vol. 31, no. 1, pp. 76-81, 2012.

[5] B. Li, "Theory and Method of Performance-Based Seismic Design of Structures with Passive Energy Dissipation Systems," Xi,an: Xi,an University of Architecture and Technology Building, 2007.

[6] W.D. Sun, and Y. Sha, "A new type of coupled shear wall structure system with buckling-restrained brace steel coupling beam", Applied Mechanics and Materials, vol. 94-96, pp. 280-288, Sep. 2011.

[7] G. Li, B. Hu, F. Sun, and X. Guo, "Development and experimental study on domestic tji buck-restrained brace," Journal of Tongji University (Natural Science), vol. 39, no. 5, pp. 631-636, 2011.

[8] T. Liu, "Seismic Behavior Experimental Research on FiberReinforced Concrete Coupling Beams with Small Span-to-Depth Ratio," Chang'an University, Xi'an, China, 2013. 